\title{
Vapor-Assisted Micropatterning in Replica Structures: A Solventless Approach towards Topologically and Chemically Designable Surfaces**
}

\author{
By Hsien-Yeh Chen and Joerg Lahann*
}

Methods for creating micro- or nanostructured surfaces are of fundamental importance to a range of applications including electronics and biotechnology. ${ }^{[1]}$ For instance, bioanalytical diagnostic devices, such as DNA or protein arrays, ${ }^{[2,3]}$ artificial substrates to mitigate cell-growth regulation, ${ }^{[4]}$ or next-generation micro/nanofluidic systems ${ }^{[5-7]}$ will require precisely structured surfaces. ${ }^{[8,9]}$ It can be expected that further progress in these and other areas of biotechnology will continue to fuel the need for simple and scalable surface structuring methods that result in both, topologically and chemically defined surfaces. Herein, we report on a simple method for fabricating both, chemically and topologically designable surfaces based on chemical vapor deposition polymerization via softlithographic stencils or replica structures.

Over the past decade, extensive efforts have been made to create topological surface patterns using either lithographical methods on the basis of light, ${ }^{[10]}$ electron ${ }^{[11]}$ and ion beams, ${ }^{[12]}$ $\mathrm{X}$-rays, ${ }^{[13]}$ or atoms ${ }^{[14]}$ as well as printing methods, such as dip/ pen lithography, ${ }^{[15]}$ patterning via scanning probes, ${ }^{[16]}$ imprinting lithographies, ${ }^{[17,18]}$ or soft lithography. ${ }^{[19,20]}$ The latter comprises an arsenal of methods, such as microcontact printing, ${ }^{\text {[21] }}$ replica moulding, ${ }^{[22]}$ microtransfer moulding, ${ }^{[23]}$ micromoulding in capillaries, ${ }^{[24]}$ solvent-assisted micromoulding, ${ }^{[25]}$ capillary force lithography, ${ }^{[26]}$ which all rely on the use of elastomeric stamps or replica structures to transfer material from a solution onto a surface. Patterned substrates created using shadow masks included a range of different materials, such as semiconductors, ${ }^{[27-29]}$ organic metals, ${ }^{[30]}$ polymers, ${ }^{[31]}$ biomaterials ${ }^{[9]}$ or cells. ${ }^{[32-34]}$ During the last few years, we have developed a generically applicable surface modification approach based on chemical vapor deposition (CVD) polymerization, ${ }^{[35,36]}$ which relies on the deposition of reactive coatings

[*] Prof. J. Lahann, H. Y. Chen

Departments of Chemical Engineering, Materials Science and Engineering, and Macromolecular Science and Engineering University of Michigan

2300 Hayward Street, Ann Arbor, MI 48109 (USA)

E-mail: lahann@umich.edu

[**] J.L. gratefully acknowledges support from the NSF in form of a CAREER grant (DMR-0449462) and funding form the NSF under MRI program (DMR 0420785). We thank Professor Ronald G. Larson, University of Michigan, for use of the fluorescence microscope. Supporting Information is available online from Wiley InterScience or from the authors. made of functionalized poly- $p$-xylylenes. These coatings have been deposited on a range of different substrate materials and geometries, including the luminal surfaces of microchannels. ${ }^{[37-39]}$ Once reactive coatings with appropriate chemical groups are deposited on a substrate, microcontact printing ${ }^{[40]}$ or photolithography ${ }^{[38]}$ can be used for surface structuring. Reactive coatings have been useful for spatially defined immobilization of biomolecules, ${ }^{[41]}$ planar cell and protein patterning, ${ }^{[38,40]}$ and for patterning of polymer brushes. ${ }^{[42]}$ On the basis of our preliminary results ${ }^{[39]}$ as well as results obtained by others, ${ }^{[30,43,44]}$ we hypothesize that chemical and topological surface microstructures can be obtained by masking certain areas of the substrate during chemical vapor deposition polymerization and then depositing the reactive coatings only within the exposed areas.

Such an approach towards microstructures surfaces, although of intriguing conceptual simplicity, comes with a series of challenges: i) In CVD polymerization, the deposition of polymers is transport-limited and it is unclear whether the polymer can be deposited within replica structures with micrometer-scale capillaries. ii) Even though polymer films may be deposited with sufficient homogeneity, reactive groups may not be freely accessible at the interface for further surface modification. iii) The range of available microstructures may be limited to discontinuous, low-coverage features obtainable by conventional shadow masking approaches. ${ }^{[45,46]}$ iv) Even in these low coverage patterns, the deposition of discontinuous polymer films could interfere with substrate encapsulation by the CVD-deposited polymer film thereby negatively affecting the adhesion between reactive coating and substrate. v) Potential defects during polymer deposition or lift-off may further contribute to decreased pattern fidelity. ${ }^{[47-49]}$

Throughout this study, we have focused on a specific reactive coating, poly(4-pentafluoropropionyl- $p$-xylylene-co- $p$-xylylene) 3 deposited via chemical vapor deposition (CVD) polymerization to proof the concept of vapor-assisted micropatterning in replica structures (VAMPIR, Scheme 1). However, the same principles should hold for other previously established functionalized poly- $p$-xylylenes containing a wide range of different functional groups, such as amines, aldehydes, anhydrides, active esters, or alkynes. ${ }^{[40-42,50-52]}$ Prior to CVD polymerization, polydimethylsiloxane (PDMS) based replica structures or stencils designed to generate a desired surface pattern were reversibly sealed onto the substrate. The masked substrate was then placed onto a temperature-con- 
(a)
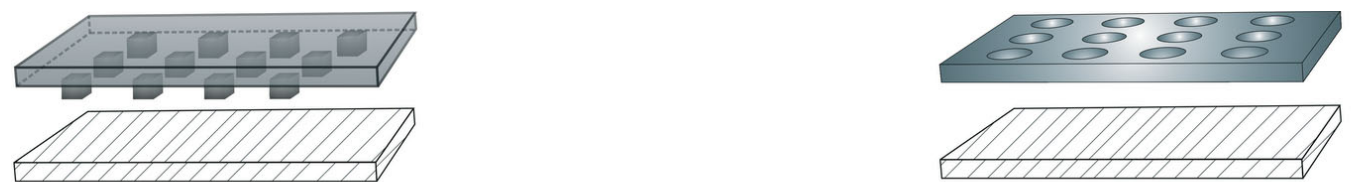

Place the replica structure
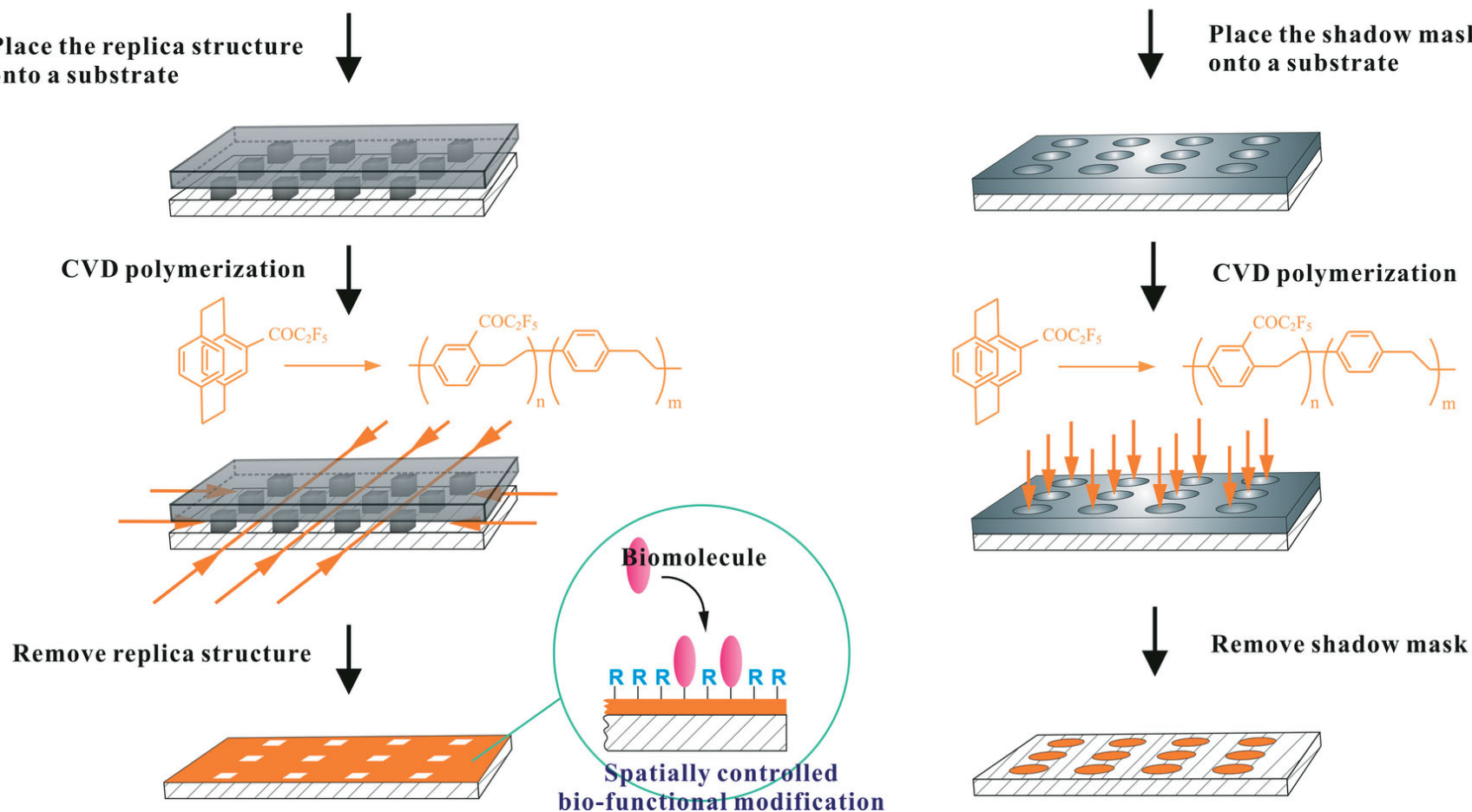

onto a substrate

(b)

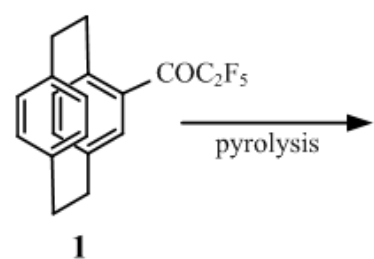

4-pentafluoropropionyl[2.2]paracyclophanes
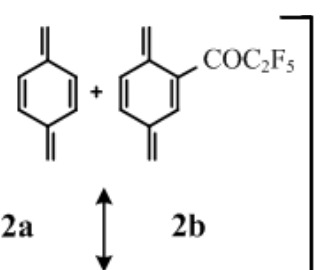<smiles>CCc1ccc(CC)c([C+]2C=C(C)C(C(=O)OC(F)(F)F)=CC2CC)c1</smiles>

deposition

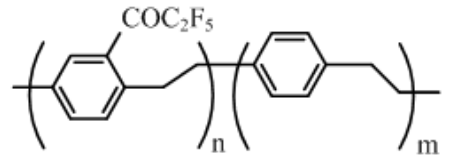

3

Poly(4-pentafluoropropionyl-p-xylylene-co-p-xylylene)

Scheme 1. a) Process of vapor-assisted microstructuring using replica structures (left column) as well as shadow masks (right column) during CVD polymerization. b) Chemical vapor deposition (CVD) polymerization reaction used to deposit poly (4-pentafluoropropionyl-p-xylylene-co-p-xylylene).

trolled stage $\left(15^{\circ} \mathrm{C}\right)$ inside of the CVD polymerization chamber. Using an adaptation of the commercially exploited Gorham process $^{[53]}$ (Scheme 1b), 4-pentafluoropropionyl[2.2]paracyclophane (1) was first sublimed and the resulting vapor was transferred into the pyrolysis zone. Starting materials $\mathbf{1}$ was synthesized from commercially available [2.2]paracyclophane via one-step synthesis adapting previously established synthesis conditions. ${ }^{[35]}$ During CVD polymerization, polymer growth rates on freely accessible surfaces were estimated to be about $1.0 \AA \mathrm{A} \mathrm{s}^{-1}$ based on in situ quarz microbalance analysis. The CVD process was further monitored using in situ mass spectrometry. Under the conditions reported for CVD polymerization, mass peaks at $104 \mathrm{~g} \mathrm{~mol}^{-1}$ and $250 \mathrm{~g} \mathrm{~mol}^{-1}$ corresponding to the quinodimethanes $\mathbf{2 a}$ and $\mathbf{2 b}$ were detected. In 
contrast, no signal was found at $354 \mathrm{~g} \mathrm{~mol}^{-1}$ excluding the presence of uncleaved paracyclophane 1. The latter suggests that the selected process conditions indeed yield quantitative cleavage of the starting material 1. After completion of the CVD polymerization and subsequent removal of the PDMS molds, a chemically and topologically structured surface was created. Surface features were defined by the deposited polymer footprints (Fig. 1). Initially, we masked the substrate with a PDMS membrane, which had circular 500 micrometers openings. Subsequent CVD polymerization resulted in localized islands of ultra-thin polymer films. Similar shadow masks or stencils were previously applied for area-selective deposi-

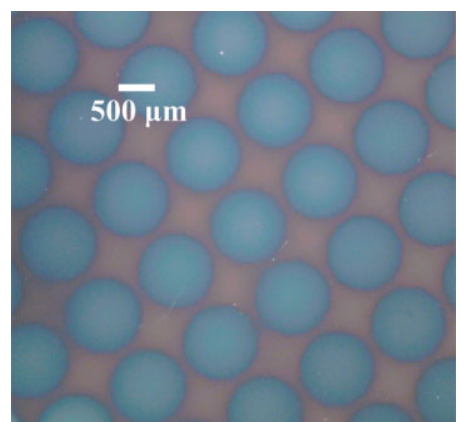

Figure 1. Optical image of microstructured surface patterns by using a shadow mask. The image shows a circular pattern of a CVD polymerized poly(4-pentafluoropropionyl-p-xylylene-co-p-xylylene) on a silicon substrate.

tion using both rigid and elastomeric materials. ${ }^{[30,44,47]}$ While many of these pattern processes are limited to hydrophilic polymers soluble in polar solvents - apolar solvents will swell elastomeric masks -, the solvent-free process described here can be used for both hydrophilic and hydrophobic coatings.

Chemical analysis of the as-deposited polymer films using a combination of X-ray photoelectron spectroscopy (XPS) and FTIR spectroscopy confirmed the proposed structure of poly(4-pentafluoropropionyl- $p$-xylylene-co- $p$-xylylene) To characterize the resulting polymer films, we utilized infrared reflection absorption spectroscopy (IRAS). The data reveal characteristic bands of the carbonyl stretches at $1714 \mathrm{~cm}^{-1}$ and C-F stretches at $1165,1191,1232 \mathrm{~cm}^{-1}$. In addition, signals at 2867,2941 , and $3039 \mathrm{~cm}^{-1}$ indicative of aliphatic methylene groups $(\mathrm{C}-\mathrm{H})$ were also detected. ${ }^{[36]}$ A XPS survey spectrum was acquired for quantitative evaluation of $F_{1 s}$, $\mathrm{O}_{1 \mathrm{~s}}$, and $\mathrm{C}_{1 \mathrm{~s}}$, and the data indicate 73.6 atom-\% carbon, 5.2 atom-\% oxygen, and 21.2 atom-\% fluorine. These values compare well with the theoretical values of 76.0 atom- $\%$ for carbon, 4.0 atom- $\%$ for oxygen, and 20.0 atom- $\%$ for fluorine. The high-resolution $\mathrm{C}_{1 \mathrm{~s}}$ spectrum after curve fitting of the $\mathrm{C}_{1 \mathrm{~s}}$ envelope further reveals characteristic signals for aliphatic and aromatic carbon ( $\underline{\mathrm{C}}-\mathrm{C}, \underline{\mathrm{C}}-\mathrm{H})$ normalized to $285.0 \mathrm{eV}$ at $83.0 \%$ atomic concentration, which compares well with the theoretical concentration of $84.1 \%$. Similarly, carbonyl carbon $(\underline{\mathrm{C}}=\mathrm{O}, 288.4 \mathrm{eV})$ at $5.1 \%$ atomic concentration, $\underline{\mathrm{C}}-\mathrm{F}_{2}$ at
$290.9 \mathrm{eV}$ with $5.0 \%$ atomic concentration, and $\mathrm{C}-\mathrm{F}_{3}$ at $293.4 \mathrm{eV}$ with $4.7 \%$ atomic concentration are all in good accordance with the theoretical values. A signal indicating $\pi \rightarrow$ $\pi^{*}$ transitions at $291.8 \mathrm{eV}$ was also found, which is characteristic for aromatic molecules and has been previously reported for similar poly- $p$-xylylenes. ${ }^{[36,54]}$ These findings are in accordance with our earlier work regarding the CVD polymerization of substituted [2.2]paracyclophanes, which typically showed close to theoretical compositions of the resulting functionalized poly- $p$-xylylenes. ${ }^{[36]}$ As shown in Figure 1, the spatially controlled CVD polymerization results in homogenous polymer patterns with little variation with respect to shape of individual elements over large surface areas $\left(3 \times 3 \mathrm{~cm}^{2}\right)$. Moreover, pattern fidelity does not appear to be compromised by the lift-off of the PDMS membrane, as indicated by the rather sharp contour lines between masked and unmasked areas. The thickness of the polymer elements can be controlled by the amount of starting material used for CVD polymerization. Typical thicknesses are in the range of 40 to $400 \mathrm{~nm}$. The thickness of the polymer structures shown in Figure 1 is $90 \mathrm{~nm}$ as determined by imaging ellipsometry.

Next, we examined the stability of the polymer patterns by immersing them in a range of different solvents, including methanol, ethanol, acetone, and chloroform; and studying their chemical structure via IRAS. For all solvents investigated in this study, the polymers were stable and the FTIR spectra before and after solvent exposure were close to identical within the margins of error. Moreover, by using a tape test in conjugation with a visual inspection, ${ }^{[50]}$ we assessed stability of a $50 \mathrm{~nm}$ thick patterned polymer film. Again, the patterns showed remarkable stability. Finally, the availability of the pentafluoropropionyl groups was assessed by probing reactivity based on immobilization of fluorescence-labeled model proteins followed by fluorescence imaging. For this reason, we conducted a series of reaction steps that initially involved the covalent binding of a biotin hydrazide followed by the surface-directed self-assembly of rhodamine-labeled strepdavidin. The fluorescence images reveal high contrast between polymer-coated and masked (uncoated) areas suggesting effective reactivity of the deposited polymer islands. Based on these experiments we concluded that (i) a simple masking of the substrate via PDMS membranes can result in large-scale structuring of surfaces with discontinuous features; and (ii) the technology is equally applicable to a wide range of substrates including silicon, glass, gold, PDMS, or polystyrene. While this simple masking approach may provide a promising access route to spatially confined polymer patterns, the use of membrane-type stencils is still restricted to rather uncomplicated, discontinuous patterns. For larger, continuous features however, the applicability of shadow masks is inherently impractical. $^{[45]}$

With the feasibility of selective polymer deposition and the stability of the resulting discontinuous polymer thin films demonstrated, we continued our studies by extending the CVD technology to large-coverage replica structures with interconnected topological features, such as more complicated, 
continuous patterns (Scheme 1, right side). Replica structures used in this approach are made of PDMS and are fabricated with microcapillaries as topological features. During the first step, the elastomeric replica structure has to be brought in intimate contact with the substrate surface. In the subsequent CVD polymerization step, the vapor-based monomers enter the replica structures and polymerize on vacant surface areas. Figure 2 shows results of imaging X-ray photoelectron spectroscopy and imaging ellipsometry for a silicon substrate modified by a continuous $100 \times 100 \mu \mathrm{m}^{2}$ grid made of reactive coating 3. The polymer patterns were further characterized using FTIR and XPS analysis and were again in accordance with the expected structure of poly(4-pentafluoropropionyl- $p$ xylylene-co-p-xylylene) (3, chemical structure shown in Scheme 1). The XPS imaging analysis reveals spatially confined distribution of fluorine as indicated by the $\mathrm{F}_{1 \mathrm{~s}}$ signal at $689.9 \mathrm{eV}$. Fluorine is a reporter atom for reactive coating 3, which contains about $21 \%$ fluorine due to its side group functionalization. As seen in Figure 2, the fluorine-containing areas unambiguously correspond to substrate regions not masked during CVD polymerization. In contrast, no fluorine was detected on the areas masked during CVD polymerization. A rather sharp contour line between masked and unmasked areas can be observed resulting in high pattern fidelity. In accordance with these data, only areas that were covered with the PDMS replica structure during CVD poly- merization showed detectable amounts of silicon as indicated by the distribution of the $\mathrm{Si}_{2 \mathrm{p}}$ signal at $150.0 \mathrm{eV}$ (Silicon is an indicator of the substrate, but is not present in the reactive coating). Moreover, imaging ellipsometry unambiguously revealed selective deposition in the unmasked areas. As shown in Figure 2c and d, substantial thickness differences, $41 \mathrm{~nm}$ in the example of Figure 2, can be observed between coated polymer areas and the silicon background. Moreover, the thickness map revealed high pattern fidelity over large-scale surface areas confirming the results obtained by imaging XPS.

To address the question of whether polymer films deposited within micorchannels still maintain their typical reactivity towards corresponding binding partners, we complimented the physico-chemical analysis with a series of immobilization studies. Reactive coating $\mathbf{3}$ has keto groups that can react with hydrazines or hydrazides in high yields. ${ }^{[55]}$ We used a model ligand, hydrazide-derived biotin, for immobilization onto the functionalized polymer films. In a subsequent step, the wellknown interactions between biotin and streptavidin are used for visualization of surface-immobilized biotin. To examine the immobilization of biotin ligands within the patterns, we allowed both rhodamine (TRITC) conjugated streptavidin and streptavidin-conjugated CdSe quantum dots (Qdot 525) to bind to the biotin-modified surfaces. Binding was homogenous throughout the surface-modified areas. Occasionally, the interfaces between coated and uncoated areas had slightly higher fluorescence, which can be attributed to proteins bound to the vertical wall at the step between CVD film and substrate. As anticipated, after biotin immobilization, the subsequently self-assembled strepdavidin was resolved into a range of different pre-designed patterns shown in Figure 3.

Once the fabrication of microstructured surfaces using CVD polymerization in replica structures was demonstrated, the lower limit of feature sizes accessible with VAMPIR could be evaluated. We therefore prepared a PDMS replica structure with varying distances between posts resulting in feature sizes of $150 \mu \mathrm{m}, 100 \mu \mathrm{m}$, $50 \mu \mathrm{m}$, and $25 \mu \mathrm{m}$, respectively. The rationale for the choice of dimension was based on the previously reported result that CVD polymers can penetrate $100 \mu \mathrm{m}$ wide microchannels. ${ }^{[39]}$ Figure 4 shows a substrate after VAMPIR-modification analyzed by a combination of imaging XPS, imaging ellispometry, and fluorescence microscopy. The composition map from imaging XPS confirms that silicon $\left(\mathrm{Si}_{2 \mathrm{~s}}\right.$, $150.0 \mathrm{eV}$ ) is only detectable for areas that were masked during CVD polymer- 
(a)

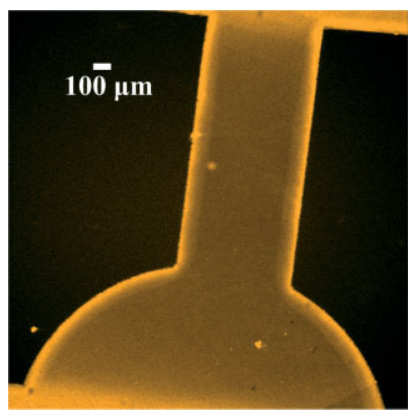

(d)

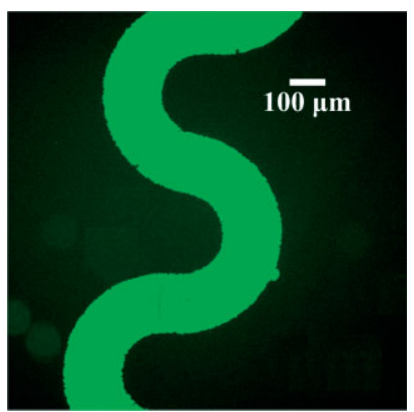

(b)

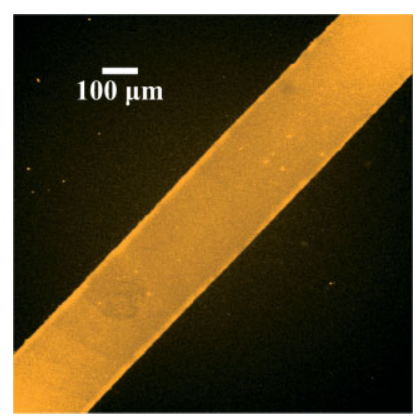

(e)

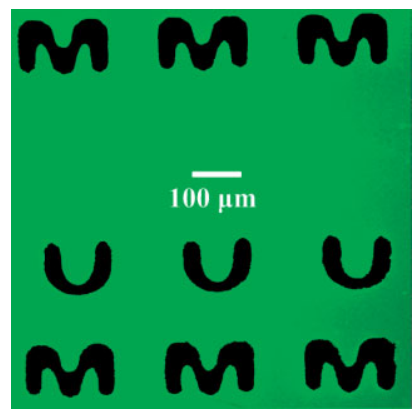

(c)

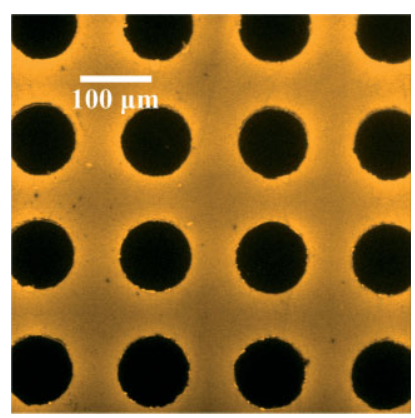

(f)

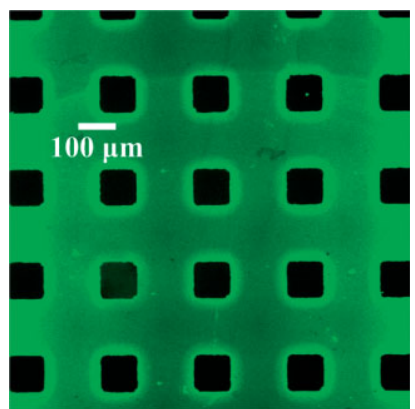

Figure 3. Fluorescence micrographs of a range of different surface patterns created through the VAMPIR process followed by immobilization of hydrazide-biotin and self-assembled strpetavidin. a)-c) are showing TRITC conjugated streptavidin self-assembly on VAMPIR structures. d)-f) are showing CdSe quantum dots conjugated streptavidin self-assembled onto VAMPIR structures.

ization, while the entire polymer footprint is devoid any detectable amounts of silicon as shown in Figure 4a. This holds for the entire range of feature sizes from 150 to $25 \mu \mathrm{m}$. Correspondingly, fluorine, a representative element for reactive coating $\mathbf{3}$ was detected only on areas not masked during CVD polymerization. The XPS results were further confirmed by imaging ellipsometry. Thicknesses of the deposited polymer coatings were measured in the center of each region. As expected, the thickness decreased from $49.6 \mathrm{~nm}$ measured for the area with $150 \mu \mathrm{m}$ feature sizes, over $42 \mathrm{~nm}(100 \mu \mathrm{m})$ and $28.7 \mathrm{~nm}(50 \mu \mathrm{m})$, to $7.3 \mathrm{~nm}$ measured for the areas with $25 \mu \mathrm{m}$ wide features. The coating thickness distribution for different feature sizes can be expressed in a relative co-ordinate system (Fig. S1, Supporting Information). ${ }^{[56,57]}$ Rearrangement of the thickness data in terms of dimensionless thicknesses $\delta(x) / \delta_{0}$ and width $(\mathrm{x} / \mathrm{b})$ - where $\delta(\mathrm{x}) / \delta_{0}$ denotes the ratio of the absolute film thickness at the given point $\mathrm{x}$ to that at the open surface, and $x / b$ is the ratio of depth over width of the feature - reveals a uniform behavior. As indicated in Figure S1, the dimensionless thicknesses measured for feature sizes ranging from $25 \mu \mathrm{m}$ to $200 \mu \mathrm{m}$, are falling onto a single trend line. This behavior suggests process parameters, but not feature size, to be dominating. This behavior is in accordance with the theoretical studies by Tolstopyatov et al., who found universal thickness distributions for the deposition of unfunctionalized poly- $p$-xylylene in microchannels. ${ }^{[56,57]}$
While the results obtained by imaging ellipsometry suggest a lower feature size of about $25 \mu \mathrm{m}$, a more functional evaluation is needed in order to ensure that these coatings can still support effective immobilization. To address this question, we conducted immobilization studies with a model ligand, hydrazide-derived biotin, on the microstructures surfaces (experiments were conducted for $150 \mu \mathrm{m}, 100 \mu \mathrm{m}, 50 \mu \mathrm{m}, 25 \mu \mathrm{m}$ ). Figure $4 d$ shows the corresponding polymer patterns after biotin immobilization and subsequent self-assembly of strepdavidin. Interestingly, similar reactivity was found independent of the thickness of the deposited polymer film suggesting that even for features sizes of $25 \mu \mathrm{m}$, effective surface immobilization is obtained. To further elucidate this matter, we investigated the quality of features in the centre areas of the replica structure; i.e., areas farthest away from the inlets were monomers had to travel longest distances prior to deposition. By virtue of the process, these areas are most prone to film defects because of the inherently transport-limited character of the VAMPIR process. For this reason, imaging XPS element mapping was examined on the smallest $25 \mu \mathrm{m}$ regions in more details (Fig. S2, Supporting Information). Three areas at or around the centre of the sample were compared. Region 1 (Fig. S2a, denotes as red colour) examined the area farthest away from the centre, and both $\mathrm{F}_{1 \mathrm{~s}}$ and $\mathrm{Si}_{2 \mathrm{~s}}$ element maps are clearly resolved. For regions 2 and 3, XPS imaging still reveals high contrast and excellent resolution for fluorine originating from the reactive coating, but reduced contrast for silicon. 


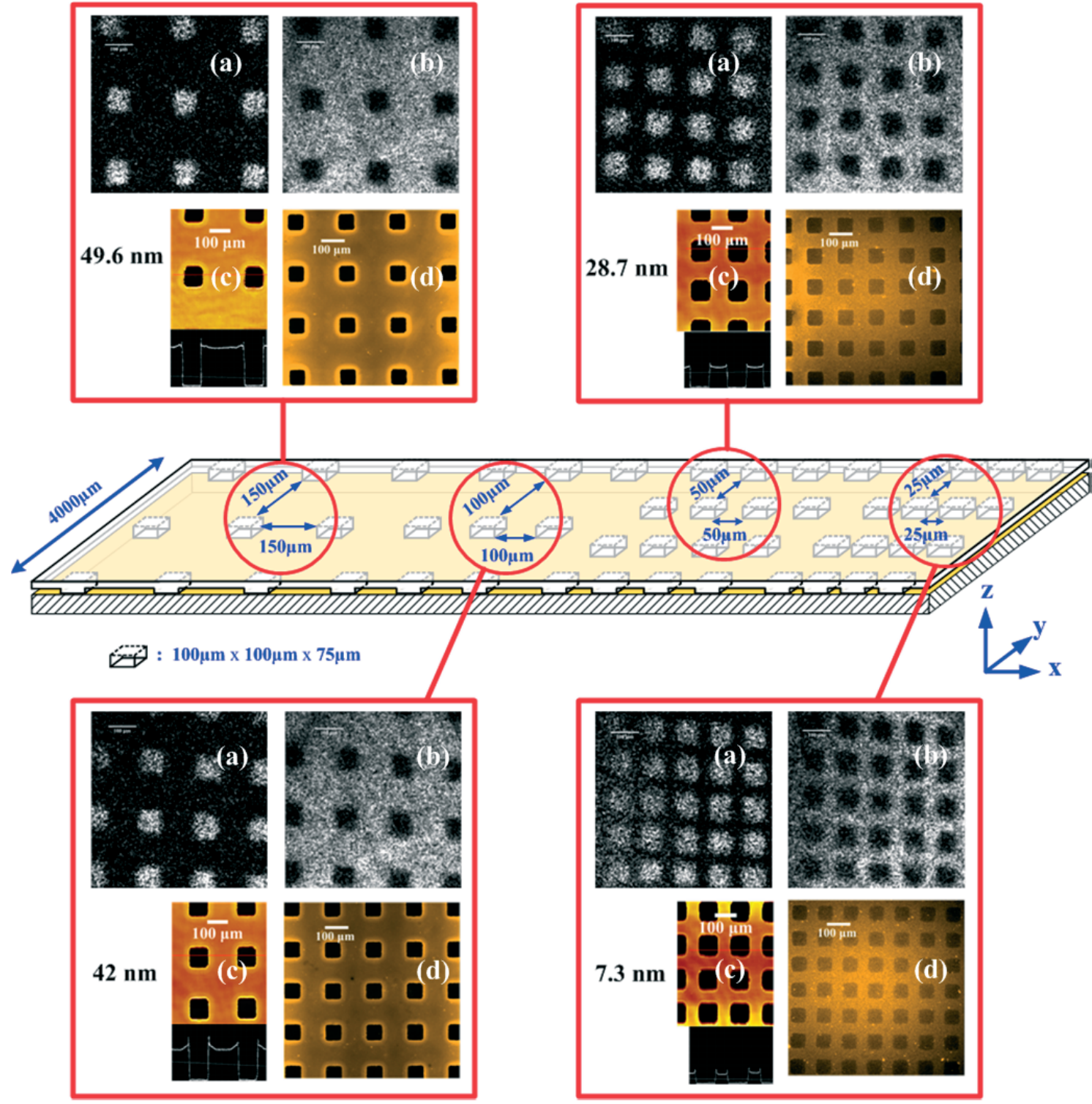

Figure 4. Influence of structure diameter on polymer depth during VAMPIR process. a) Imaging XPS $\mathrm{Si}_{2 \mathrm{~s}}(150.0 \mathrm{eV})$ elemental map. b) Imaging XPS $\mathrm{F}_{1 \mathrm{~s}}(689.9 \mathrm{eV})$ elemental map. c) Imaging ellipsometry thickness map. d) Fluorescence micrograph showing biotin/TRITC-streptavidin modification. All the scale bars denote $100 \mu \mathrm{m}$.

These data may imply that the polymer films are approaching thicknesses below $10 \mathrm{~nm}$ in the center region, which is the excepted sampling depth of XPS for polymer coatings. ${ }^{[58]}$ This is also in accordance with the earlier discussed thickness values obtained by imaging ellipsometry as well as the homogeneous surface coverage obtained by subsequent chemical modification. The fact that homogeneous surface structures with feature sizes as small as $25 \mu \mathrm{m}$ can be obtained may have important implications when developing robust tools for tailoring surface properties.

Vapor-assisted microstructuring in replica structures (VAMPIR) establishes a simple technique to create both, chemical and topological surface patterns. The process is essentially independent of the (solid) substrate material and re- lies solely on masking certain areas of the substrate during chemical vapor deposition polymerization and then depositing the reactive coatings only within the exposed areas. Our study further reveals that this process is applicable to a range of different structures, including both continuous and discontinuous features with feature sizes as small as $25 \mu \mathrm{m}$. For all features examined in this study, the adhesion between reactive coating and substrate was excellent and was not affected by exposure to standard solvents. Similarly, excellent pattern fidelity was observed within the entire feature range and no negative impact due to lift-off of the replica structures was observed. Most importantly, reactive side groups present in the polymer can serve as anchoring sites for subsequent surface modifications. Therefore, the resulting reactive surface pat- 
terns could provide a precisely confined microenvironment for biological applications, and may create an essential tool for the precise control towards effective bio-functional modifications. In future, surface properties can be further tailored by changing the type of reactive coating used during the VAMPIR process. This will provide a wide range of choices to ensure use of functional groups most optimally suited for a specific application. ${ }^{[36,59,60]}$

\section{Experimental}

Device Fabrication: The replica structures were designed using AutoCAD, and the design was printed on high-resolution emulsion transparencies (40,640 DPI, Photoplot Store). For fabrication of the master, a layer of photoresist (SU-8 2050, MicroChem Co.) was spincoated at $2000 \mathrm{rpm}$ for $30 \mathrm{~s}$ onto a silicon wafer. The wafer was softbaked at $65^{\circ} \mathrm{C}$ for $3 \mathrm{~min}$ followed by $95^{\circ} \mathrm{C}$ for $9 \mathrm{~min}$, and the wafer was then exposed to UV radiation $\left(404.7 \mathrm{~nm}, 10 \mathrm{~mJ} \mathrm{~cm}^{-2}\right)$ for $4 \mathrm{~min}$ to define the desired microstructure from the transparency mask. Post exposure bake was preformed at $65^{\circ} \mathrm{C}$ for 1 min followed by $95^{\circ} \mathrm{C}$ for $7 \mathrm{~min}$. After removal of the activated photoresist by exposition to a SU-8 developer solution (MicroChem Co.) for $7 \mathrm{~min}$ with agitation the resulting SU-8 master was cleaned with isopropyl alcohol (IPA), and then was dried with compressed air. The resulting silicon master was placed in a Petri dish and uniformly mixed PDMS prepolymer and curing agent (Sylgard 184, Dow Corning) at a ratio of 10:1 were poured onto the SU-8 master. The PDMS prepolymer was cured at $70{ }^{\circ} \mathrm{C}$ for $1 \mathrm{~h}$. Finally, embossed microgeometries were released from the SU-8 master. The replicated PDMS molds and silicon substrates were brought into contact and the resulting devices were placed onto the sample chamber for CVD polymerization. The fabricated PDMS molds were $75 \mu \mathrm{m}$ high, $4000 \mu \mathrm{m}$ long in y direction, and has different width dimension of $150 \mu \mathrm{m}, 100 \mu \mathrm{m}, 50 \mu \mathrm{m}$, and $25 \mu \mathrm{m}$ (as illustrated in Fig. 2)

CVD Polymerization: Poly(4-pentafluoropropionyl- $p$-xylylene-co$p$-xylylene) (3) was synthesized via CVD polymerization (Scheme 1). The starting material, 4-pentafluoropropionyl [2.2]paracyclophane (1), was sublimed under vacuum and converted by pyrolysis into the corresponding quinodimethanes $\mathbf{2 a}$ and $\mathbf{2 b}$, which spontaneously polymerized upon condensation to the substrate surface. A HPR-30 mass spectrometer (Hiden Analytical, U.K.) was connected to the deposition chamber for in situ analysis. Mass spectra were recorded at $1000 \mu \mathrm{A}$ emission and $70.0 \mathrm{~V}$ electron energy using a faraday detector scanning from $100 \mathrm{~g} \mathrm{~mol}^{-1}$ to $500 \mathrm{~g} \mathrm{~mol}^{-}$. A constant argon flow of $20 \mathrm{sccm}$ was used as the carrier. Sublimation temperatures were kept at $70{ }^{\circ} \mathrm{C}$ followed by pyrolysis at $670{ }^{\circ} \mathrm{C}$. Subsequently, polymerization occurred on a rotating, cooled sample holder placed inside a stainless steel chamber with a wall temperature of $120^{\circ} \mathrm{C}$. The coating pressure was 0.12 Torr or below. The exit of the chamber was connected via a cooling trap to a mechanical pump. For CVD polymerization, PDMS molds were sealed reversibly to a silicon wafer, which was placed onto the sample holder.

Poly(4-pentafluoropropionyl-p-xylylene-co-p-xylylene) (3): IR (grazing angle of $85^{\circ}$ ): $\tilde{v}=832,943,1066,1140,1165,1191,1232,1351$, 1453, 1497, 1566, 1610, 1714, 2867, 2941, $3039 \mathrm{~cm}^{-1}$; XPS survey: C, $73.6 \%$ (76.0\% calcd); O, $5.2 \%$ ( $4.0 \%$ calcd); F, $21.2 \%(20.0 \%$ calcd); XPS high resolution $\mathrm{C}_{1 \mathrm{~s}}:-\mathrm{C}-\mathrm{H}$ at $285.0 \mathrm{eV} 83.0 \%(84.1 \%$ calcd); $-\mathrm{C}=\mathrm{O}$ at $288.4 \mathrm{eV}, 5.1 \%\left(5.3 \%\right.$ calcd.); $-\mathrm{C}-\mathrm{F}_{2}$ at $290.9 \mathrm{eV}$, $5.0 \%$ (5.3\% calcd.); $-\mathrm{C}_{-} \mathrm{F}_{3}$ at $293.4 \mathrm{eV}, 4.7 \%$ (5.3\% calcd); $\pi-\pi^{*}$ at $291.8 \mathrm{eV}, 2.2 \%$.

Surface Characterizations: X-ray photoelectron spectroscopy (XPS) data were recorded on an Axis Ultra X-ray photoelectron spectrometer (Kratos Analyticals, UK) equipped with a monochromatized Al $\mathrm{K} \alpha \mathrm{X}$-ray source. In these experiments, the lens mode was in hybrid, pass energy was set to $160.0 \mathrm{eV}$, and the aperture was $600 \mu \mathrm{m} \times$ $600 \mu \mathrm{m}$ for all imaging acquisitions. Elemental maps of fluorine $\left(F_{1 \mathrm{~s}}\right)$ and silicon $\left(\mathrm{Si}_{2 \mathrm{~s}}\right)$ were performed at 689.9 and $150.0 \mathrm{eV}$, respectively, with an X-ray power of $150 \mathrm{~kW}$. Thickness profile analysis data were recorded using an single wavelength $(532 \mathrm{~nm}) \mathrm{EP}^{3}-\mathrm{SW}$ imaging ellipsometry (Nanofilm Technologie $\mathrm{GmbH}$, Germany). Both, nulling (four zones) and mapping experiments were performed at an angle of incident of $65^{\circ}$, and a constant $\mathrm{n}$ (refractive index) and $\mathrm{k}$ (extinction coefficient) value model was used to model the ellipsometric parameters psi and delta. For the mapping mode, data were recorded by an imaging scanner with a lateral resolution of $1 \mu \mathrm{m}$ at a field of view of about $200 \mu \mathrm{m} \times 600 \mu \mathrm{m}$. The images were captured using a CCD camera $(768 \times 572$ pixels $)$.

Bio-Functional Modifications: Reaction with biotin ligands followed by binding to streptavidin was used to visualize the resulting patterns. Based on this procedure, samples were incubated in Petri dishes with biotin-hydrazide (10 mM, Pierce) in phosphate buffered saline (PBS, $\mathrm{pH}$ 7.4) for $5 \mathrm{~min}$. The surface was then rinsed several times with PBS. After rinsing, devices were incubated with rhodamine (TRITC) conjugated streptavidin $\left(10 \mu \mathrm{g} \mathrm{mL}^{-1}\right.$, Pierce) in PBS containing $0.1 \%(\mathrm{w} / \mathrm{v})$ bovine albumin and Tween $20(0.02 \%(\mathrm{v} / \mathrm{v}))$ for $60 \mathrm{~min}$. On the other hand, streptavidin-conjugated quantum dots (CdSe) $(1 \mu \mathrm{M}$, Qdot 525, Quantum Dot Co.) were also incubated as another set of experiment in order to prove the concept. Both surfaces were rinsed several times with PBS containing $0.1 \%(\mathrm{w} / \mathrm{v})$ bovine albumin and Tween $20(0.02 \%(\mathrm{v} / \mathrm{v}))$. The resulting samples were then examined by fluorescence microscopy (TE 200, Nikon).

Received: December 12, 2006

Revised: June 13, 2007

Published online: October 30, 2007

[1] M. A. Burns, B. N. Johnson, S. N. Brahmasandra, K. Handique, J. R. Webster, M. Krishnan, T. S. Sammarco, P. M. Man, D. Jones, D. Heldsinger, C. H. Mastrangelo, D. T. Burke, Science 1998, 282 , 484.

[2] J. D. Tian, H. Gong, N. J. Sheng, X. C. Zhou, E. Gulari, X. L. Gao, G. Church, Nature 2004, 432, 1050.

[3] J. P. Pellois, X. C. Zhou, O. Srivannavit, T. C. Zhou, E. Gulari, X. L. Gao, Nat. Biotechnol. 2002, 20, 922.

[4] C. S. Chen, M. Mrksich, S. Huang, G. M. Whitesides, D. E. Ingber, Science 1997, 276, 1425

[5] S. Takayama, J. C. McDonald, E. Ostuni, M. N. Liang, P. J. A. Kenis, R. F. Ismagilov, G. M. Whitesides, Proc. Natl. Acad. Sci. USA 1999 96, 5545.

[6] E. M. Lucchetta, J. H. Lee, L. A. Fu, N. H. Patel, R. F. Ismagilov, Nature 2005, 434, 1134.

[7] T. Thorsen, S. J. Maerkl, S. R. Quake, Science 2002, 298, 580.

[8] N. H. Mack, R. Dong, R. G. Nuzzo, J. Am. Chem. Soc. 2006, 128, 7871.

[9] B. R. Ringeisen, J. Callahan, P. K. Wu, A. Pique, B. Spargo, R. A. McGill, M. Bucaro, H. Kim, D. M. Bubb, D. B. Chrisey, Langmuir 2001, 17, 3472.

[10] P. Rai-Choudhury, Handbook of Microlithography, Micromachining, and Microfabrication, Vol. 1, SPIE, London, UK 1997

[11] N. Yao, Z. L. Wang, Handbook of Microscopy for Nanotechnology, Springer, New York, NY 2005

[12] A. A. Tseng, Small 2005, 1, 594.

[13] F. Cerrina, J. Phys. D 2000, 33, R103.

[14] D. Meschede, H. Metcalf, J. Phys. D 2003, 36, R17.

[15] D. S. Ginger, H. Zhang, C. A. Mirkin, Angew. Chem. Int. Ed. 2004 43,30 .

[16] S. Kraemer, R. R. Fuierer, C. B. Gorman, Chem. Rev. 2003, 103 , 4367.

[17] S. Y. Chou, P. R. Krauss, P. J. Renstrom, Appl. Phys. Lett. 1995, 67, 3114.

[18] S. Y. Chou, P. R. Krauss, P. J. Renstrom, Science 1996, 272, 85

[19] Y. N. Xia, G. M. Whitesides, Annu. Rev. Mater. Sci. 1998, 28, 153.

[20] A. Kumar, G. M. Whitesides, Appl. Phys. Lett. 1993, 63, 2002. 
[21] J. L. Wilbur, A. Kumar, E. Kim, G. M. Whitesides, Adv. Mater. 1994, 6,600 .

[22] Y. N. Xia, E. Kim, X. M. Zhao, J. A. Rogers, M. Prentiss, G. M. Whitesides, Science 1996, 273, 347.

[23] X. M. Zhao, Y. N. Xia, G. M. Whitesides, Adv. Mater. 1996, 8, 837.

[24] E. Kim, Y. N. Xia, G. M. Whitesides, Nature 1995, 376, 581.

[25] E. Kim, Y. N. Xia, X. M. Zhao, G. M. Whitesides, Adv. Mater. 1997, 9, 651 .

[26] K. Y. Suh, Y. S. Kim, H. H. Lee, Adv. Mater. 2001, 13, 1386.

[27] W. T. Tsang, A. Y. Cho, Appl. Phys. Lett. 1978, 32, 491.

[28] T. Schallenberg, T. Borzenko, G. Schmidt, M. Obert, G. Bacher, C. Schumacher, G. Karczewski, L. W. Molenkamp, S. Rodt, R. Heitz, D. Bimberg, Appl. Phys. Lett. 2003, 82, 4349.

[29] S. De Vusser, S. Steudel, K. Myny, J. Genoe, P. Heremans, Appl. Phys. Lett. 2006, 88.

[30] D. C. Duffy, R. J. Jackman, K. M. Vaeth, K. F. Jensen, G. M. Whitesides, Adv. Mater. 1999, 11, 546.

[31] N. Takano, L. M. Doeswijk, M. A. F. van den Boogaart, J. Auerswald, H. F. Knapp, O. Dubochet, T. Hessler, J. Brugger, J. Micromech. Microeng. 2006, 16, 1606.

[32] E. Ostuni, R. Kane, C. S. Chen, D. E. Ingber, G. M. Whitesides, Langmuir 2000, 16, 7811.

[33] R. Pal, K. E. Sung, M. A. Burns, Langmuir 2006, 22, 5392.

[34] D. G. Castner, B. D. Ratner, Surf. Sci. 2002, 500, 28.

[35] J. Lahann, D. Klee, H. Hocker, Macromol. Rapid Commun. 1998, 19, 441.

[36] J. Lahann, R. Langer, Macromolecules 2002, 35, 4380.

[37] J. Lahann, M. Balcells, H. Lu, T. Rodon, K. F. Jensen, R. Langer, Anal. Chem. 2003, 75, 2117.

[38] H.-Y. Chen, J. Lahann, Anal. Chem. 2005, 77, 6909.

[39] H. Y. Chen, Y. Elkasabi, J. Lahann, J. Am. Chem. Soc. 2006, 128, 374.

[40] J. Lahann, M. Balcells, T. Rodon, J. Lee, I. S. Choi, K. F. Jensen, R. Langer, Langmuir 2002, 18, 3632.

[41] J. Lahann, H. Hocker, R. Langer, Angew. Chem. Int. Ed. 2001, 40 726.
[42] J. Lahann, I. S. Choi, J. Lee, K. F. Jenson, R. Langer, Angew. Chem. Int. Ed. 2001, 40, 3166.

[43] R. J. Jackman, D. C. Duffy, O. Cherniavskaya, G. M. Whitesides, Langmuir 1999, 15, 2973.

[44] H. W. Gu, R. K. Zheng, X. X. Zhang, B. Xu, Adv. Mater. 2004, 16, 1356.

[45] A. Tixier, Y. Mita, J. P. Gouy, H. Fujita, J. Micromech. Microeng 2000, 10, 157.

[46] T. Schallenberg, C. Schumacher, S. Gundel, W. Faschinger, Thin Solid Films 2002, 412, 24.

[47] M. Graff, S. K. Mohanty, E. Moss, A. B. Frazier, J. Microelectromech. Syst. 2004, 13, 956.

[48] G. M. Kim, M. A. F. van den Boogaart, J. Brugger, Microelectron. Eng. 2003, 67-8, 609.

[49] Y. X. Zhou, A. T. Johnson, Nano Lett. 2003, 3, 1371.

[50] H. Nandivada, H. Y. Chen, J. Lahann, Macromol. Rapid Commun. 2005, 26, 1794.

[51] H. Nandivada, H. Y. Chen, L. Bondarenko, J. Lahann, Angew. Chem. Int. Ed. 2006, 45, 3360.

[52] K. Schurmann, J. Lahann, P. Niggemann, B. Klosterhalfen, J. Meyer, A. Kulisch, D. Klee, R. W. Gunther, D. Vorwerk, Radiology 2004, $230,151$.

[53] W. F. Gorham, J. Polym. Sci. Polym. Chem. Ed. 1966, 4, 3027.

[54] Y. Elkasabi, H. Y. Chen, J. Lahann, Adv. Mater. 2006, 18, 1521.

[55] G. T. Hermanson, Bioconjugate Techniques, Academic, San Diego, CA 1996.

[56] E. M. Tolstopyatov, J. Phys. D 2002, 35, 1516.

[57] E. M. Tolstopyatov, S. H. Yang, M. C. Kim, J. Phys. D 2002, 35, 2723.

[58] D. Briggs, Surface Analysis of Polymers by XPS and Static SIMS, Cambridge University Press, Cambridge 1998.

[59] M. Yoshida, R. Langer, A. Lendlein, J. Lahann, Polym. Rev. 2006, $46,347$.

[60] J. Lahann, Chem. Eng. Commun. 2006, 193, 1457. 